University of Wollongong

Research Online

Faculty of Social Sciences - Papers (Archive) Faculty of Arts, Social Sciences \& Humanities

2016

Perceptions of task interdependence and functional leadership in schools

Kerry Barnett

University of New South Wales

John McCormick

University of Wollongong, johnmcc@uow.edu.au

Follow this and additional works at: https://ro.uow.edu.au/sspapers

Part of the Education Commons, and the Social and Behavioral Sciences Commons

Research Online is the open access institutional repository for the University of Wollongong. For further information contact the UOW Library: research-pubs@uow.edu.au 


\title{
Perceptions of task interdependence and functional leadership in schools
}

\author{
Abstract \\ The context of the research was senior leadership teams in schools in Australia. The study investigated \\ relationships between task interdependence, psychological collectivism, self-efficacy for teamwork, and \\ team member perceptions of leadership functions. A cross-sectional and correlational research design \\ was employed. Fifty-seven senior leadership teams composed of principals and senior teachers within \\ two Catholic education systems in New South Wales, Australia, participated in the study. Data were \\ collected from an online survey completed by senior leadership team members and analyzed using \\ multilevel data analysis strategies. The findings suggest the extent of functional leadership was positively \\ related to perceived task interdependence. \\ Keywords \\ functional, leadership, schools, interdependence, task, perceptions \\ Disciplines \\ Education | Social and Behavioral Sciences \\ Publication Details \\ Barnett, K. \& McCormick, J. (2016). Perceptions of task interdependence and functional leadership in \\ schools. Small Group Research: an international journal of theory, investigation and application, 47 (3), \\ 279-302.
}


Perceptions of Task Interdependence and Functional Leadership in Schools

\author{
Kerry Barnett \\ University of New South Wales \\ John McCormick \\ University of Wollongong \\ Corresponding author: k.barnett@unsw.edu.au
}

\title{
Author Biographies
}

Kerry Barnett is a lecturer in the Educational Leadership Program in the School of Education at the University of New South Wales, Australia. Her research focuses on applying group and team process theory to leadership in educational contexts.

John McCormick is an Honorary Professorial Fellow of the University of Wollongong. His research has focused on motivation, including stress and leadership, with particular reference to group and team cognitive processes.

Keywords: Team Leadership, Task Interdependence, Psychological Collectivism, Self-Efficacy for Teamwork

Acknowledgements: The authors wish to acknowledge the assistance of Dr Mark Turkington (Regional Director, Catholic Education Office, Southern Region) and Mr Peter Turner (Regional Director, Diocese of Wollongong) in facilitating this study, and also the contribution of the principals and teachers who participated in this study. 


\begin{abstract}
The context of the study was senior leadership teams in schools in Australia. The study investigated relationships between task interdependence, psychological collectivism, self-efficacy for teamwork, and team member perceptions of leadership functions. A cross sectional and correlational research design was employed. Fifty seven senior leadership teams composed of principals and senior teachers within two Catholic education systems in New South Wales Australia participated in the study. Data were collected from an online survey completed by senior leadership team members and analyzed using multi-level data analysis strategies. The findings suggest the extent of functional leadership was positively related to perceived task interdependence.
\end{abstract}


Perceptions of Task Interdependence and Functional Leadership in Schools

Work in schools is increasingly organized around teams, whereby two or more people interact interdependently to achieve common goals (Kozlowski \& Bell, 2003). Teams generally are considered potentially effective because they can bring together diverse skills, expertise, and experience necessary to tackle the exceptional complexities of school environments. However, for any team to be effective, much depends on members achieving team synergy and coherence of actions (Zaccaro, Heinen \& Shuffler, 2009). Thus, getting people to work well together is a challenge that must be addressed because team effectiveness is likely to be determined by synergistic team member actions, and this focuses attention on the factors that might influence the performance of individuals working in teams.

Several scholars (Kozlowski, Watola, Jensen, Kim \& Botero, 2009; Zaccaro et al., 2009) have argued leadership is central to the development and support of team processes that contribute to successful team performance because it facilitates team coordination. Recent research evidence (Barnett \& McCormick, 2012; Burke et al., 2006; DeRue, Nahrgang, Wellman \& Humphrey, 2011) has emphasized the significance of leadership for successful team effectiveness. Further, some researchers (Burke et al., 2006; Fleishman et al., 1992; Kozlowski, Gully, Salas \& Cannon Bowers, 1996a; Zaccaro, Rittman \& Marks, 2001) have identified three broad leadership functions: direction setting, managing team operations, and developing team self-management capacity, considered critical for team effectiveness. Despite the contribution made by these studies towards understanding leadership in team settings, the extent to which leadership functions matter (or not) for team effectiveness is likely to be determined by context (DeRue, Barnes \& Morgeson, 2010; Kozlowski \& Bell, 2003). While the broader environmental and organizational contexts have been emphasized in the literature (Kozlowski \& Bell, 2003), the 
team context is likely to be the most salient for leadership because it is the most immediate one. Moreover, even if the broader context were important its effect is likely to be mediated through team context, as team members by 'virtue of their cognition, affect, behavior, and interaction processes enact structural features, such as norms, expectations and roles which serve as team generated contextual constraints’ (Kozlowski \& Bell, 2003, p.55). Therefore, we posit that team context has not been given enough attention and needs to be more fully investigated.

Our aim was to deepen current understanding of leadership functions in team settings and contribute new insights by investigating senior leadership teams in school contexts, where extant research is scarce. Thus, the purpose of this study, part of a larger investigation of senior leadership teams (SLTs) in Catholic systemic schools in New South Wales, Australia, was to investigate relationships between team context, specifically task interdependence, psychological collectivism, self-efficacy for team work, and team member perceptions of leadership functions. In this study, we defined the 'senior leadership team' as the group that meets with the principal to make decisions for the whole school.

The rest of the article is organized into three parts, the first reviews relevant literature, outlines the conceptual framework and hypotheses investigated in the study. The second part describes research methods, presents results and discussion, and the last, discusses the study's limitations, conclusions, and implications for research and practice.

\section{Literature Review}

\section{Functional Leadership}

Most studies of team leadership have adopted a functional view of leadership (Burke et al., 2006). This view contends that, 'it is [the leader's] main job to do, or get done, whatever is not being adequately handled for group needs’ (McGrath, 1962, p. 5). Further, functional leadership emphasizes 'what needs to be done' rather than, 'what should be done', it does not try to specify 
behaviors to accomplish key leadership functions, and it does not attempt to specify who should enact these functions (Hackman \& Walton, 1986, Zaccaro et al., 2009).

A number of researchers (e.g., Fleishman et al., 1992; Hackman \& Walton, 1986; Hackman, 2002; Kozlowski et al., 1996a; Zaccaro et al., 2001) have extended functional leadership theory. The early work of Hackman and Walton (1986), Hackman (2002), and Fleishman et al., (1992) has been reflected in more recent studies on team leadership (e.g., Burke et al., 2006; Kozlowski et al., 2009; Morgeson, DeRue \& Karam, 2010; Zaccaro et al., 2009), which have suggested three core leadership functions: direction setting, management of team operations, and developing team and team member capacity to manage their own problem solving processes, are critical to team effectiveness.

Most of the recent work on team leadership has been conceptual (e.g., Kozlowski et al., 2009; Zaccaro et al., 2009). Of interest to this empirical study, is a series of conceptual models by Kozlowski et al., (1996a) and Kozlowski, Gully, McHugh, Salas \& Cannon-Bowers, (1996b), and Kozlowski et al., (2009), which integrate leadership functions with team task and developmental dynamics to develop a meta-theory of team leadership. An important aspect of this work is that it considers and specifies the dynamic contingencies which may influence the focus and application of leadership functions.

One of the contingencies considered by Kozlowski et al., (2009) is task dynamics. These researchers posited 'team tasks are not fixed, rather, they cycle episodically in terms of complexity and load they place on team member resources (cognitive, behavioral, and motivational) engaged as the team works to accomplish goals’ (Kozlowski et al., 2009, p. 116). The episodic and cyclical nature of team tasks provides an opportunity for leaders to shape team processes underlying team effectiveness (Kozlowski et al., 2009). Thus, 'during low load, ideally, leaders carry out the function of setting developmental goals, monitor and intervene as necessary 
during high load, and diagnose deficiencies and provide feedback as team tasks cycle back to low load’ (Kozlowski et al., 2009, p. 117). Other researchers (e.g., Marks, Mathieu \& Zaccaro, 2001) conceptualized a two phase team task cycle: a transition phase, which centers on evaluating prior performance and planning for future activities, (placing a low load on team member resources), and an action phase in which members engage in activities directly related to goal accomplishment (placing a high load on member resources). The two phases are dependent on the nature of the task and may vary in duration and should determine the focus and application of leadership functions (Kozlowski et al., 2009).

Morgeson et al., (2010) contended as team members’ work together they encounter many challenges which stem from the team operating environment. Such challenges may threaten team viability and goal accomplishment because team members may be unable to regulate their behaviors (Morgeson et al., 2010). This creates needs which must be addressed for the team to successfully accomplish its goals. For example, needs created during the transition phase include developing a shared understanding of direction, goals, and the strategies to accomplish them, and in the action phase monitoring of performance, coordinating actions, engaging in high quality communication, developing capacity, and managing team boundaries (Morgeson et al., 2010). Also, across the two phases interpersonal needs related to motivation, emotions and conflict may occur within the team (Morgeson et al., 2010).

Adopting a functional view of leadership, Morgeson et al., (2010) conceptualized leadership as a process of team need satisfaction to enhance team effectiveness. Thus, it is the role of the leader to satisfy team needs during the transition and action phases of the team task cycle. Following a review of the team leadership literature, Morgeson et al., (2010) developed a framework of fifteen leadership functions that can help to satisfy team needs in the transition and 
action phases of the team task cycle. We limit the remainder of this discussion to leadership functions relevant to the transition phase of the team task cycle as this was the focus of this study.

Morgeson et al., (2010) proposed seven leadership functions relevant to team need satisfaction in the transition phase of the team task cycle: (1) ensuring the team has the right mix of people to accomplish goals, (2) defining the team's mission so that a shared understanding of team goals is developed, team members see themselves as part of the team and cohesive relationships are developed, (3) establishing performance expectations and setting goals, (4) structuring and planning the team's work so team members share an understanding of how best to coordinate individual actions, (5) ensuring all team members are capable of performing well, (6) making sense of the team's operating environment, interpreting events and communicating this to the team, and (7) facilitating feedback processes in the team.

Whilst the conceptual models and framework developed by Kozlowski et al., 1996a, 1996b, 2009, and Morgeson et al., (2010) provide important insights into team leadership given certain task dynamics, they are limited because they lack empirical support. This reflects the team leadership literature generally, in which conceptual understanding has outpaced empirical evidence, and there appears little appreciation for the importance of context, and in particular team context in the application of team leadership functions. Team context is likely to be shaped by individual team members' perceptions of task interdependence, and individual team members' attributes, such as psychological collectivism and self-efficacy for teamwork, which may augment or constrain the appropriateness or effectiveness of team leadership functions. These aspects of team context are discussed in the following sections.

\section{Task Interdependence}

Task interdependence is the degree to which team members must rely on, and interact with each other to accomplish their tasks effectively (Campion, Medsker \& Higgs, 1993; Saavedra, 
Earley \& Van Dyne, 1993). Task interdependence may refer to the objective degree to which team members depend on one another to perform tasks effectively, or team members' subjective impressions of task interdependence (LeDoux, 2009).

Most of the literature on task interdependence appears to focus on the 'objective' structure, whereby task interdependence is determined by the characteristics of a task (e.g., Janz, Colquitt \& Noe, 1997; Thompson, 1967). However, several researchers (e.g., Shea \& Guzzo, 1987) have emphasized that groups and teams often exercise discretion in establishing levels of interaction and cooperation necessary for effective task performance, so that the degree of task interdependence may vary, even in apparently identical task environments (Gully, Incalcaterra, Joshi \& Beaubien, 2002). As a result, it has been suggested task interdependence may not only be related to task characteristics, and the way work is organized, but also to the way in which people work together (Ramamoorthy \& Flood, 2004). Drach-Zahavy \& Somech (2010) have contended while task interdependence may be an objective structure, it is likely team members will also attend to social cues, such as the behaviors of leaders and other team members, who 'signal to them how to perceive, interpret and behave' (p.150). Thus, task interdependence is more likely to be 'a blend of objective cues and subjective perceptions of team members' efforts to understand them’ (Drach-Zahavy \& Somech, 2010, p. 150).

Whilst we agree that for a given team task interdependence may be conceptualized as an 'objective' task structure, we argue that individual team members' perceptions of the extent to which a task is interdependent are more salient. Indeed, our argument is consistent with the socalled Thomas Theorem (McCall, 2013), which asserts that individuals’ perceived realities are indeed real for them, and so their consequences are real.

Task interdependence has been shown to be an important moderator of team processes which contribute to team effectiveness (e.g., Barrick, Bradley, Kristoff-Brown \& Colbert, 2007, 
Gully et al., 2002, Langfred, 2005, Saavedra et al., 1993, and Van Der Vegt, Emans \& Van De Vliert, 2000). In addition, meta-analytical findings (e.g., Burke et al., 2006) have shown that when task demands are high, communication and collaboration demands on team members tend to increase dramatically, necessitating a need for leaders to monitor and coordinate team member actions. We describe how we extend this work in the description of the conceptual framework.

\section{Psychological Collectivism}

Historically, collectivism was conceptualized at the cultural level (Hofstede, 1984). However, as the organization of work has shifted to teams, arguably, collectivism has become more important in team contexts (Chen, Chen \& Meindl, 1998; Dierdorff, Bell \& Belohlav, 2011). Generally, collectivists see group interests as more important than individual needs or desires, and tend to look out for the well-being of groups to which they belong, even when such actions involve sacrificing personal interests (Wagner \& Moch, 1986). Some scholars (e.g., Chen et al., 1998; Earley \& Gibson, 1998; LePine, Hanson, Borman \& Motowidlo, 2000) have suggested, because of the emphasis collectivists place on shared responsibility, collectivism should be related positively to team performance. A number of studies (e.g., Campion et al., 1993; Eby \& Dobbins, 1997) have provided empirical support for this contention prompting some scholars (e.g., Driskell \& Salas, 1992; Miles, 2000) to conclude that a collectivistic orientation likely influences the performance of individuals in teams (Wagner, Humphrey, Meyer \& Hollenbeck, 2012).

Despite the findings discussed above, there have been problems with the psychometric properties of collectivism instruments designed for work contexts (Earley \& Gibson, 1998). In response, Jackson, Colquitt, Wesson \& Zapata-Phelan (2006) developed and validated a measure of collectivism for the work setting, and provided findings that support the importance of this construct for teams. Based on previous work (e.g., Triandis, 1995), collectivism was 
conceptualized as an individual difference construct with five facets and labelled psychological collectivism. The five facets were, preference (collectivists value relationships with others and prefer to work in groups), concern (collectivists are motivated by group interest rather than selfinterest), reliance (collectivists are comfortable relying on others), norm acceptance (collectivists focus on group rules to foster cooperation in the group), and goal priority (collectivist actions are guided by group interests so group goals take priority over individual goals). Jackson et al., (2006) reported empirical support for the new psychological collectivism measure, and importantly found team members with a collectivist orientation generally performed group tasks better, contributed more to team citizenship, and were less likely to engage in counterproductive behaviors. This finding is consistent with previous research (e.g., Campion et al., 1993; Eby \& Dobbins, 1997).

\section{Self-efficacy for Teamwork}

Hackman \& Wageman (2005) suggested the level of effort team members apply carrying out task work contributes to team performance. A substantial body of research has demonstrated self-efficacy in work settings is a strong predictor of the amount of effort expended by, and

persistence of, individuals, particularly in the face of challenging circumstances (Bandura, 1997). Further, other research (e.g., Stajkovic \& Luthans, 1998) has reported a moderate effect size ( $d=.34)$ between self-efficacy and work related performance.

According to Bandura (1986), self-efficacy is domain specific and refers to ‘a person’s judgement of her/his capability to organize and execute courses of action attaining designated types of performance' (p.391). Self-efficacy for teamwork can be defined as a team member’s belief in her or his capability to work in a team to accomplish team goals. In the context of a team, individuals’ self-efficacy for teamwork is likely to have implications for team work, and possibly team outcomes, because individual team members bring these attributes to the team. 
Individuals with high self-efficacy for teamwork are likely to put in effort and persist in working with other team members, while team members with lower self- efficacy for teamwork may be less likely to put in effort and persist in working with team members to accomplish team goals. Further, a team likely will reflect the attributes of the people who are its members, and a combination of individual team members' self-efficacy for teamwork is likely to create a contextual structure which may enhance or constrain subsequent team processes and outcomes (McClough \& Rogelberg, 2003).

\section{Conceptual Framework and Hypotheses}

Our conceptual framework was developed from the literature. Specifically, this framework proposes task interdependence, psychological collectivism and self-efficacy for team work shape the extent to which team members perceive the principal to enact team functions relevant to the transition phase of the team task cycle.

First, previous meta-analytical work has suggested task interdependence positively predicts team leadership functions (Burke et al., 2006). However, task demands and interdependencies may not necessarily be in a steady state, and are likely to be sensitive to external factors and different phases of the team task cycle. In the transition phase of the team task cycle, team members need to work together to establish and develop a shared understanding of goals, structures, plans and processes that will enable the team to perform effectively in the future. If this involves a high level of task complexity it will necessitate higher degrees of integration, coordination and interdependence among team members. A higher degree of task interdependence is likely to place a heavier load on team member resources (cognition, behavior and motivation) as team members must communicate, collaborate and interact more often in a coherent fashion to accomplish team goals. Further, this is likely to necessitate a need for monitoring, coordination and development of team member capacity, and so creates an 
environment for a principal to enact team leadership functions, which assist team members to regulate behavior coherently for goal accomplishment. Therefore, the higher the degree of task interdependence the more likely the team will need to communicate, collaborate and interact to complete a team task, and the more likely the relevant leadership functions will be enacted by a principal, and vice versa. Hence, we propose the following hypothesis:

H1: Task interdependence will positively predict team member perceptions of the extent to which the principal enacts team leadership functions in the transition phase of the team task cycle.

Second, given the importance collectivists place on team membership and the needs of groups, they will tend to value being part of the team, will naturally affiliate with the team, and place team goals above their own (Wagner, 1995). Thus, the higher team members’ psychological collectivism, the more likely they will be open to, accepting of, and respond positively to, team leadership functions enacted by a principal, which by definition focus on helping the team integrate and coordinate individual actions to accomplish team goals. Further, this relationship is also likely to be shaped by the extent to which team members perceive whether the enactment of team leadership functions actually promotes quality interaction, generates appropriate strategies for group task accomplishment, and develops team capacity. Therefore it is hypothesized:

H2: Psychological collectivism will positively predict team member perceptions of the extent to which the principal enacts team leadership functions in the transition phase of the team task cycle. 
Last, in the transition phase of the team task cycle, a principal is likely to facilitate team performance through specific leadership functions, defining the mission, establishing expectations and setting goals, and structuring and planning. Defining the mission establishes a common understanding with regard to direction, goal specification provides a target for performance, and structuring and planning assist the team in determining how, by whom, and when, the work will be done. Team members with high self-efficacy for teamwork are more likely to believe themselves capable of accomplishing goals, and are more likely to consider and expect a principal to enact supportive team leadership functions. In addition, they are more likely to put in effort and persist until team goals are achieved. Thus, higher levels of self-efficacy for team work are likely to be associated with positive perceptions of the enactment of team leadership functions which assist team members to accomplish goals. Therefore, it is hypothesized:

H3: Self-efficacy for teamwork will positively predict team member perceptions of the extent to which the principal enacts team leadership functions in the transition phase of the team task cycle.

\section{Method}

\section{Design, Procedures and Sample}

We employed a cross-sectional correlational research design and multilevel techniques to analyse data. Permissions were obtained from university, school authorities and instrument developers. We invited 89 SLTs, each composed of principal, deputy principal, and coordinators, through two systemic Catholic Education Offices in the Sydney and Wollongong metropolitan areas, New South Wales, Australia to participate in the study. In Australia, Catholic schools are either independent or part of a system. Each system is embedded within a Diocese. Australia has 
33 Dioceses with the central bureaucracy for schools located within a Catholic Education Office in each Diocese.

A total of 70 SLTs agreed to participate in the study, providing approximately an $79 \%$ response rate. The participants were members of the SLT in each school. We excluded 13 teams with fewer than three responses from team members (Zhang, Hempel, Han \& Tjosvold, 2007). The final sample comprised 57 SLTs, the average team size was six members $(\mathrm{SD}=2.8)$, and the mean team tenure was 2.5 years $(\mathrm{SD}=1.7)$.

Data were collected by an online survey completed anonymously. The survey included measures of perceived task interdependence, psychological collectivism, and self-efficacy for teamwork. In addition, all team members except the principal completed measures of perceived team leadership functions.

\section{Measures}

Task interdependence was assessed with a five-item scale adopted from Langfred (2005). The scale measured three aspects of perceived task interdependence, the extent to which team success is determined by team members working together, team members coordinating actions with each other, and the extent to which a team member's work is affected by the work of other team members. Examples of items are, 'to be successful the senior leadership team needs to coordinate its work' and 'most of my work activities are affected by the work of other people in the senior leadership team'. We asked participants to refer specifically to the SLT. Participants responded on a five-point scale ranging from not true at all (0) to true to a very great extent (4).

Psychological collectivism was measured with a 15 item scale adapted from Jackson et al., (2006). This scale measured five facets of psychological collectivism: preference for group work, reliance on the group, concern for the well-being of the group, acceptance of group norms and group goal priority. Sample items are, 'I preferred to work in groups rather than working alone' 
(preference); 'I have accepted the rules of groups to which I belong' (acceptance); 'I have felt comfortable counting on group members to do their part' (reliance); 'I was concerned about the needs of those groups' (concern), and 'Group goals were more important to me than my personal goals’ (goals). Participants were asked to refer to the SLT and other work groups to which they had belonged in the past. They responded on a five point rating scale ranging from not true at all (0) to true to a very great extent (4).

Self-efficacy for teamwork was determined by a 13 item scale comprising nine items focused on perceptions of capability to work, contribute, communicate, delegate responsibility, coordinate tasks, resolve conflict, integrate ideas, take on a leadership role, and be effective in that role. Nine items were adapted from Eby and Dobbins (1997) and four items, focused on perceptions of ability to monitor self and team member performance, support team members, and align mission, were derived from Marks et al., (2001). We asked participants to refer to their own experiences of working in a team and rate how confident they were with regard to working in a team. For example, 'Coordinate tasks and activities of a team', 'Facilitate communication between people' and 'Monitor my own performance'. Participants responded on an 11 point rating scale, which ranged from no confidence $(0 \%)$ to complete confidence (100\%).

Perceptions of extent to which the principal performed transition phase team leadership functions were assessed with an 84 item scale adapted from the team leadership questionnaire (Morgeson et al., 2010). For this study, we measured six dimensions of transition phase team leadership: define mission, sense-making establish expectations and goals, structure and plan, professional growth of team members, and provide feedback. Examples of items were, 'Ensures the team has a clear direction' (mission), 'Facilitates team understanding of events or situations' (sense-making), 'Communicates school issues to the team' (feedback), 'Defines team expectations' (expectations), 'Helps new team members learn how to do the work of a team' 
(professional growth), 'Structures the work of the team' (structuring). Senior leadership team members were asked to rate their perceptions of the extent to which the principal displayed team leadership functions on a five point scale, which ranged from not at all true $(0)$ to true to a very great extent (4).

\section{Analysis}

Given the hierarchical nature of the data (individuals nested within teams), multilevel analysis was the primary data analytic strategy employed. We developed a series of measurement models using Lisrel 9.1 to determine if task interdependence, psychological collectivism, selfefficacy for teamwork, and team leadership measures captured distinct variables. The measurement models were estimated with diagonally weighted least squares (Jöreskog, 1990) because preliminary data analysis showed violations of distributional assumptions underlying the commonly used maximum likelihood approach. The $\chi^{2}$ statistic was used to compare the fit of solutions (Brown, 2006). Latent variable scores were generated with Lisrel 9.1 (Jöreskog, 2000). To test the hypotheses, we used Hox’s (2010) multilevel modeling procedure which involved starting with a simple unconditional model and proceeding by adding parameters, one at a time testing for significance, after they have been added, at each step.

\section{Results}

Measurement Models: Table 1 presents the fit indices for hypothesized and alternate models. There are several points to be made about Table 1. First, hypothesized models for team leadership (define mission, sense-making, establish expectations and goals, provide feedback and grow team members) generally fitted the data well. Second, the hypothesized models for task interdependence and team leadership (structure and plan) did not fit the data well. As shown in 
Table 1, alternative models were estimated in which one indicator was removed from each of the hypothesised models for task interdependence and team leadership (TL). The model fit indices and corresponding $\chi^{2}$ difference tests $(\mathrm{p}<.05)$ shown in Table 1 suggested the alternative models fitted the data significantly better than the hypothesized models for task interdependence and team leadership (structure and plan).

$<$ Insert Table 1 here $>$

Third, the results in Table 1 show the hypothesized five factor model for psychological collectivism did not fit the data well. Four nested models were estimated, resulting in a two factor model that matched hypothesized factors; fit indices and $\chi^{2}$ difference tests suggested the final two factor psychological collectivism model (preference and acceptance) was a better fit for these data.

Last, the hypothesized model for self-efficacy for teamwork also did not fit the data well. Three alternate models, in which one indicator was removed at a time, were estimated. The final model fitted the data significantly better, as indicated by a $\chi^{2}$ difference test $(\mathrm{p}<.05)$, and is shown in Table 1.

In summary, the measurement models’ fit indices, and $\chi^{2}$ difference tests (see Table 1 ) supported the discriminant validity of task interdependence, psychological collectivism, selfefficacy for teamwork, and team member perceptions of team leadership measures. Descriptive Statistics: The descriptive statistics, internal consistency estimates are presented in Table 2. There are two noteworthy results. First, Cronbach alpha estimates suggest high levels of internal consistency for most constructs (task interdependence, self-efficacy for teamwork and transition team leadership functions), although, the Cronbach alpha for psychological 
collectivism (acceptance) ( $\alpha=.56)$ is relatively low. We decided to retain psychological collectivism (acceptance) because the factor was part of the original instrument, Cronbach alpha generally may be depressed when there are a small number of items (Raykov, 1998), and most importantly, we considered the scale theoretically sound. Second, Table 2 shows high correlations between team leadership constructs. However, this was not problematic because the team leadership variables were employed as dependent variables.

$<$ Insert Table 2 about here $>$

Multilevel Modeling: All models were estimated using full information maximum likelihood (FML) in Lisrel 9.1. FML estimation provides parameter estimates and corresponding standard errors, which can be used to determine statistical significance of explanatory variables and include both regression coefficients and variance components in the likelihood function, from which a deviance statistic can be calculated to show how well the data fit the model and enable comparison in model fit between nested models (Hox, 2010). At first, we estimated the interceptonly models for task interdependence, psychological collectivism, self-efficacy for teamwork and transition team leadership functions. The results in Table 3 show that statistically significant variation in all variables can be attributed to differences within teams. Thus, variation in task interdependence, psychological collectivism, self-efficacy for teamwork and leadership functions likely depends on differences in perceptions of individual team members rather than any effect of belonging to a team. However, the lack of variation for task interdependence at the team level was surprising. As a check, we calculated $\mathrm{R}_{\mathrm{wg}}$ for the interdependence variable. Interestingly, two-thirds of the teams had an $\mathrm{R}_{\mathrm{wg}}$ index greater than .7 (James, Demaree, \& Wolf, 1984), suggesting that there likely was a team level phenomenon of task interdependence, which was relatively consistent across teams. Our tentative explanation for the lack of team level variance 
was that the influence of central Catholic Education Offices had resulted in relatively uniform team activity.

$<$ Insert Table 3 here $>$

Six models were developed with each of the six dimensions of team leadership, define mission, i.e., present the organization's mission in terms of operational goals; sense-making, i.e., identify and interpret the team's context and communicate this to the team; establish expectations, i.e., set team goals; provide team feedback, i.e., provide feedback to the team and individual team members; grow team members, i.e., facilitate personal and professional development of team members; structure and plan, i.e., how work will be accomplished, as dependent variables. In developing the models, we first added level 1 explanatory variables (task interdependence, psychological collectivism [preference], psychological collectivism [acceptance], and self-efficacy for teamwork) one at a time as fixed effects, and assessed the contribution of each explanatory variable in the transition team leadership intermediate models. Intermediate and final models with each of the leadership functions are shown in Tables 4 to 9.

<Insert Tables 4-9 here>

Task interdependence is the only independent variable that is a statistically significant positive predictor of each of the six leadership functions (see Tables 4 to 9). Thus, H1 is completely supported. H2 and H3 are supported to some extent by the Pearson correlation analysis, however, no significant effects were identified in the more comprehensive multilevel models

\section{Discussion}

The primacy of task interdependence in the statistical models is striking. Essentially, the extent to which the team leader, i.e., the principal, was perceived by team members to carry out 
the six leadership functions was positively related to the extent to which the team members perceived team tasks to be interdependent. It is important not to ascribe unidirectional causality from this result. Indeed, logically, the relationship makes sense in both directions, and may best be conceptualized as dynamic in nature. When tasks were perceived to be interdependent to some extent in the transition phase of leadership functions, it is plausible that certain team 'needs' may have emerged. Defining the mission could have provided a level of coherence across team members. Similarly, sense-making may have assisted team members to establish a consensual view of the team's environment, including the individual parts required to be played by the members of the team (Weick, Sutcliffe \& Obstfeld, 2005). Setting clear expectations and providing feedback on the extent to which expectations were met, also likely enabled team members effectively to determine their own future actions, and see how they fitted with other team members. By helping team members to grow, team leaders also assisted them to become more suited to successfully playing their individual roles, and better understanding the roles of other members of the team, including the team leader. Last, by enabling structure and planning to some extent, leaders may have facilitated an effective division of (interdependent) labour within the teams. However, causality could readily be argued in the other direction. That is, the leadership functions fostered a 'need' for task interdependence.

Despite the contributions of these results, it is important to note limitations of the study because they provide directions for further research. First, while effects of common method variance arguably were minimized with the use of multiple data sources (principals and senior leadership team members), it is not possible to rule this out completely because we did not verify these data independently. Second, we recognise that we have not been able to capture the dynamic interactive nature of the relationship between aspects of team context and transition phase team leadership functions investigated in this study. Clearly, it would be desirable to 
employ a longitudinal design, which incorporates observations of senior leadership teams in action, in the transition phase of the team performance cycle in the future. However, the sample size illustrates the problems encountered in the investigation of teams in action. Last, our sample is drawn from one schooling sector within the Australian education system, which limits generalization of our findings to this sector only. Given the critical role of senior leadership teams in schools, and the significance of task interdependence for team member perceptions of transition phase team leadership functions reported in this study, an important area for future research would be to investigate task interdependence and team member perceptions of transition phase team leadership functions in senior leadership teams in other school sectors.

\section{Conclusion and Implications for Practice}

Arguably, the main conclusion that can be drawn from this study is that team members, particularly team leaders should emphasize perceived interdependence of team tasks when carrying out transition phase leadership functions. Whilst we have focused on the psychological component of task interdependence, one may reasonably argue that the most effective approach would be to build interdependence structurally into tasks, and then attempt to ensure that the interdependence is perceived and internalized by team members. In short, it would appear unwise to attempt to engender perceptions of task interdependence that have no 'objective' validity. To this end, each leadership function should have built-in task interdependence. Of course, this only makes sense when tasks are able to be made interdependent, and team members are willing to approach tasks interdependently. 


\section{References}

Barrick, M., Bradley, B., Kristof-Brown, A., \& Colbert, A. (2007). The moderating role of top management team interdependence: Implications for real teams and working groups. Academy of Management Journal, 50, 544-557. doi:10.5465/AMJ.2007.25525781.

Barnett, K., \& McCormick, J., (2012). Leadership and team dynamics in senior executive leadership teams. Educational Management Administration and Leadership, 40, 653-671. doi:10.1177/1741143212456909.

Bandura, A. (1986). Social foundations of thought and action: A social cognitive theory. Englewood Cliffs, NJ: Prentice-Hall.

Bandura, A. (1997). Self-Efficacy: The Exercise of Control. New York: W.H. Freeman.

Brown, T. (2006). Confirmatory factor analysis for applied research. New York: Guilford Press.

Burke, S., Stagl, K., Klein C., Goodwin, G., Salas, E., \& Halpin, S. (2006). What types of leadership behaviour are functional in teams? A meta-analysis. Leadership Quarterly, 17, 288-307. doi:10.1037/0021-9010.91.6.1189.

Campion, M., Medsker, G., \& Higgs, A. (1993). Relations between work group characteristics and effectiveness: Implications for designing effective work groups. Personnel Psychology, 46, 823-847. doi:10.1111/j.1744-6570.

Chen, C., Chen, X., \& Meindl, J. (1998). How can cooperation be fostered? The cultural effects of individualism-collectivism. Academy of Management Review, 23, 285-304. doi: 10.5465/AMR.1998.533227.

DeRue, D., Barnes, C., \& Morgeson, F. (2010). Understanding the motivational contingencies of team leadership. Small Group Research, 41, 621-651. doi:10.1177/1046496410373808.

DeRue, D., Nahrgang, J., Wellman, N., \& Humphrey, S. (2011). Trait and behavioral theories of leadership: An integration and meta-analytic test of their relative validity. Personnel Psychology, 64, 7-52. doi:10.1111/j.1744-6570.2010.01201.x.

Dierdorff, E., Bell, S., \& Belohlav, J. (2011). The power of “we”: Effects of psychological collectivism on team performance over time. Journal of Applied Psychology, 96, 247-262. doi:10.1037/a0020929.

Drach-Zahavy, A., \& Somech, A. (2010). From an intrateam to an interteam perspective of effectiveness: The role of interdependence and boundary activities. Small Group Research. 41, 143-174. doi:10.1177/1046496409356479

Driskell, J., \& Salas, E. (1992). Collective behavior and team performance. Human Factors: The Journal of the Human Factors and Ergonomics Society, 34, 277-288. doi: 10.1177/001872089203400303.

Earley, P., \& Gibson, C. (1998). Taking stock in our progress on individualism-collectivism: 100 years of solidarity and community. Journal of Management, 24, 265-304. doi: 10.1177/014920639802400302.

Eby, L., \& Dobbins, G. (1997). Collectivistic orientation in teams: an individual and group-level analysis. Journal of Organizational Behavior, 18, 275-295. doi:10.1002/(SICI)10991379(199705)18:3<275::AID-JOB796>3.0.CO;2-C. 
Fleishman, E., Mumford, M., Zaccaro, S., Levin. K., Korotkin, A., \& Hein, M. (1992). Taxonomic efforts in the description of leader behavior: A synthesis and functional interpretation. Leadership Quarterly, 2, 245-287. doi:10.1016/1048-9843(91)90016-U.

Gully, S., Incalcaterra, K., Joshi, A., \& Beaubien, J. (2002). A meta-analysis of team-efficacy, potency, and performance: Interdependence and level of analysis as moderators of observed relationships. Journal of Applied Psychology, 87, 819-832. doi:10.1037/0021-9010.87.5.819.

Hackman, J. (2002). Leading teams: Setting the stage for great performances. Boston, MT: Harvard Business Press.

Hackman, J., \& Walton, R. (1986). Leading groups in organizations. In P, Goodman. (Ed.). Designing Effective Work Groups (pp. 72-117). San Francisco, CA: Jossey Bass.

Hackman, J., \& Wageman, R. (2005). A theory of team coaching. Academy of Management Review, 30, 269-287. doi:10.5465/AMR.2005.16387885.

Hofstede, G. (1984). Culture's consequences: Comparing values, behaviors, institutions and organizations across nations. Beverly Hills, CA: Sage.

Hox, J. (2010). Multilevel analysis: Techniques and applications. New York: Routledge.

Jackson, C., Colquitt, J., Wesson, M., \& Zapata-Phelan, C. (2006). Psychological collectivism: a measurement validation and linkage to group member performance. Journal of Applied Psychology, 91, 884-899. doi:10.1037/0021-9010.91.4.884.

James, L., Demaree, R., \& Wolf, G. (1984). Estimating within-group interrater reliability with and without response bias. Journal of Applied Psychology, 69, 85-98. doi:10.1037/00219010.69.1.85.

Janz, B., Colquitt, J., \& Noe, R. (1997). Knowledge worker team effectiveness: The role of autonomy, interdependence, team development, and contextual support variables. Personnel Psychology, 50, 877-904. doi:10.1111/j.1744-6570.1997.tb01486.x.

Jöreskog, K. (1990). New developments in LISREL: Analysis of ordinal variables using polychoric correlations and weighted least squares. Quality \& Quantity, 24, 387-404. doi: 10.1007/BF00152012.

Jöreskog, K. (2000). Latent variable scores and their uses. Retrieved from http://www.ssicentral.com/lisrel/techdocs/lvscores.pdf.

Kozlowski, S., Gully, S., Salas, E., \& Cannon-Bowers, J. (1996a). Team leadership and development: Theory, principles, and guidelines for training leaders and teams. In M, Beyerlein., D, Johnson., \& S, Beyerlein. (Eds.). Advances in interdisciplinary studies of work teams: Team leadership, (Vol. 3, pp. 253-291). US: Elsevier Science/JAI Press.

Kozlowski, S., Gully, S., McHugh, P., Salas, E., \& Cannon-Bowers, J. (1996b). A dynamic theory of leadership and team effectiveness: Developmental and task contingent leader roles. Research in Personnel and Human Resources Management, (Vol 14, pp. 253-305). Greenwich, CT: JAI Press.

Kozlowski, S., \& Bell, B. (2003). Work groups and teams in organizations. In W, Borman., D, Ilgen., \& E, Klimoski. (Eds.). Handbook of psychology: Industrial and organizational psychology, (Vol. 12, pp. 333-375). London: Wiley. 
Kozlowski S., Watola D., Jensen, J., Kim, B., \& Botero, I. (2009). Developing adaptive teams: A theory of dynamic team leadership. In E, Salas., G, Goodwin., \& C, Shawn Burke. (Eds.). Team Effectiveness in Complex Organisations: Cross Disciplinary Perspectives and Approaches. (pp.113-155). New York: Psychology Press.

Langfred, C. (2005). Autonomy and performance in teams: The multilevel moderating effect of task interdependence. Journal of Management, 31, 513-529. doi:10.1177/0149206304272190.

LeDoux, J. (2009). Team Task Interdependence Perceptions: Toward an Integrative Model of Teamwork. (Unpublished Doctoral Dissertation). Louisiana State University, Baton Rouge, LA.

Marks, M., Mathieu, J., \& Zaccaro, S. (2001). A temporally based framework and taxonomy of team processes. Academy of Management Review, 26, 356-376. doi:10.5465/AMR.2001.4845785.

McCall, G. J. (2013). Interactionist perspectives in social psychology. In J. DeLamater \& A. Ward (Eds.). Handbook of Social Psychology. (pp. 3-29). Dordrecht: Springer.

McClough, A., \& Rogelberg, S. (2003). Selection in teams: An exploration of the teamwork knowledge, skills, and ability test. International Journal of Selection and Assessment, 11, 5666. doi:10.1111/1468-2389.00226.

McGrath, J. (1962). Leadership behavior: Some requirements for leadership training. Washington DC: Office of Career Development, US Civil Service Commission.

Miles, J. (2000). Relationships of collective orientation and cohesion to team outcomes. Psychological Reports, 86, 435-444. doi:10.2466/pr0.2000.86.2.435.

Morgeson, F., DeRue, D., \& Karam, E. (2010). Leadership in teams: A functional approach to understanding leadership structures and processes. Journal of Management, 36, 5-39. doi:10.1177/0149206309347376.

Ramamoorthy, N., \& Flood, P. (2004). Individualism/collectivism, perceived task interdependence and teamwork attitudes among Irish blue-collar employees: a test of the main and moderating effects? Human Relations, 57, 347-366, doi:10.1177/0018726704043274.

Raykov, T. (1998). Coefficient alpha and composite reliability with interrelated nonhomogeneous items. Applied Psychological Measurement, 22, 375-385. doi:10.1177/014662169802200407.

Saavedra, R., Earley, P., \& Van Dyne, L. (1993). Complex interdependence in task-performing groups. Journal of Applied Psychology, 78, 61-72. doi:10.1037/0021-9010.78.1.61.

Shea, G., \& Guzzo, R. (1987). Group effectiveness - What really matters? Sloan Management Review, 28, 25-31.

Stajkovic, A., \& Luthans, F. (1998). Self-efficacy and work-related performance: A metaanalysis. Psychological Bulletin, 124, 240-261. doi:10.1037/0033-2909.124.2.240.

Thompson, J. (1967). Organization in Action. Chicago, Ill: McGraw-Hill.

Triandis, H. (1995). Individualism \& collectivism: New directions in social psychology. Boulder, CO: Westview Press. 
Van Der Vegt, G., Emans, B., \& Van De Vliert, E. (2000). Team members’ affective responses to patterns of intragroup interdependence and job complexity. Journal of Management, 26, 633655. doi:10.1177/014920630002600403.

Wagner, J., \& Moch, M. (1986). Individualism-collectivism: Concept and measure. Group \& Organization Management, 11, 280-304. doi:10.1177/105960118601100309.

Wagner, J. (1995). Studies of individualism-collectivism: Effects on cooperation in groups. Academy of Management Journal, 38, 152-173, doi:10.2307/256731.

Wagner, J., Humphrey, S., Meyer, C., \& Hollenbeck, J. (2012). Individualism-collectivism and team member performance: Another look. Journal of Organizational Behavior, 33, 946-963, doi:10.1002/job.783.

Weick, K., Sutcliffe, K., \& Obstfeld, D. (2005). Organizing and the process of sense-making. Organization Science, 16, 409-421. doi:10.1287/orsc.1050.0133

Zaccaro, S., Heinen, B., \& Shuffler, M. (2009). Team leadership and team effectiveness. In E, Salas., G, Goodwin., \& C. Shawn Burke. (Eds.). Team Effectiveness in Complex Organisations: Cross Disciplinary Perspectives and Approaches. (pp. 83-111). New York: Psychology Press.

Zaccaro, S., Rittman, A., \& Marks, M. (2001). Team leadership. Leadership Quarterly 12, 451483. doi:10.1016/S1048-9843(01)00093-5.

Zhang, Z., Hempel, P., Han, Y., \& Tjosvold, D. (2007). Transactive memory system links work team characteristics and performance. Journal of Applied Psychology, 92, 1722-1730.

doi:10.1037/0021-9010.92.6.1722. 
Table 1.

Fit indices for measurement models

\begin{tabular}{lccccc}
\hline Variable & $d f$ & $\chi^{2}$ & CFI & RMSEA & SRMR \\
\hline Task Interdependence & 2 & .51 & 1.00 & .00 & .01 \\
Psychological Collectivism & 8 & $23.09 *$ & .99 & .00 & .04 \\
Self-efficacy Teamwork & 35 & 15.45 & 1.00 & .00 & .02 \\
TL (Define Mission) & 5 & .71 & 1.00 & .00 & .00 \\
TL (Sense-making) & 9 & $22.12^{*}$ & 1.00 & .00 & .02 \\
TL (Expectations) & 44 & $280.65 * *$ & .99 & .01 & .03 \\
TL (Team Feedback) & 9 & $34.96 * *$ & 1.00 & .00 & .03 \\
TL(Grow Members) & 5 & 6.61 & 1.00 & .00 & .01 \\
TL(Structure \& Plan) & 5 & $26.08^{* *}$ & .99 & .04 & .02 \\
\hline
\end{tabular}

Note. $d f=$ degrees of freedom, $\chi^{2}=$ chi square statistics, RMSEA=root mean square error of approximation, SRMR=standardized root mean square residual, ${ }^{*} \mathrm{p}<.05,{ }^{* *} \mathrm{p}<.001$ 
Table 2.

Descriptive statistics, internal consistency reliability and correlations

\begin{tabular}{|c|c|c|c|c|c|c|c|c|c|c|c|c|}
\hline Variable & $\mathrm{M}$ & SD & 1 & 2 & 3 & 4 & 5 & 6 & 7 & 8 & 9 & 10 \\
\hline 1. Task Interdependence & 2.69 & 1.04 & .77 & & & & & & & & & \\
\hline 2. PC(Preference) & 2.77 & .97 & .09 & .73 & & & & & & & & \\
\hline 3. PC(Acceptance) & 3.20 & .85 & .12 & .27 & .56 & & & & & & & \\
\hline 4. Self-efficacy Team & 87.57 & 10.22 & .07 & .10 & .22 & .89 & & & & & & \\
\hline 5. TL(Define Mission & 3.33 & .83 & .14 & .19 & .28 & .31 & .94 & & & & & \\
\hline 6. TL(Sense-making) & 3.24 & .79 & .15 & .14 & .20 & .23 & .75 & .93 & & & & \\
\hline 7. TL(Expectations) & 3.29 & .83 & .18 & .11 & .29 & .29 & .93 & .79 & .96 & & & \\
\hline 8. TL (Team Feedback) & 3.24 & .84 & .16 & .11 & .31 & .25 & .79 & .78 & .83 & .92 & & \\
\hline 9. TL(Grow Members) & 3.22 & .80 & .14 & .20 & .29 & .26 & .82 & .78 & .84 & .81 & .90 & \\
\hline 10. TL(Structure \& Plan) & 3.22 & .83 & .13 & .20 & .31 & .30 & .86 & .79 & .89 & .79 & .82 & .90 \\
\hline
\end{tabular}

Note. $\mathrm{M}=$ raw mean, $\mathrm{SD}=$ standard deviation, correlations in bold are significant, $\mathrm{p}<.05$, bold and italics are significant, $\mathrm{p}<.01$ (one-tailed), and Cronbach alphas are on diagonal. 
Table 3

Variance components model for 10 variables showing proportion of between-team and withinteam residual variance: 314 teachers in 57 schools.

\begin{tabular}{lcccccc}
\hline Variable & \multicolumn{2}{c}{ Fixed } & \multicolumn{3}{c}{ Random (residual variance) } \\
\cline { 2 - 6 } & \multicolumn{2}{c}{ Intercept } & \multicolumn{2}{c}{ Between-team } & \multicolumn{2}{c}{ Within-team } \\
& $\Upsilon_{00}$ & S.E & $\sigma_{\mathrm{u} 0}{ }^{2}$ & S.E & $\sigma_{\mathrm{e}}{ }^{2}$ & S.E \\
\cline { 2 - 6 } Task Interdependence & $2.43^{* *}$ & .22 & -.22 & .51 & $14.97^{* *}$ & 1.30 \\
PC(Preference) & $3.09^{* *}$ & .13 & .24 & .20 & $3.98^{* *}$ & .35 \\
PC(Acceptance) & $3.25^{* *}$ & .14 & .29 & .23 & $4.74^{* *}$ & .42 \\
Self-efficacy Teamwork & $95.37^{* *}$ & 1.18 & -9.71 & 14.68 & $431.74^{* *}$ & 37.61 \\
TL(Define Mission) & $-1.12^{*}$ & .35 & -1.94 & 1.32 & $38.75^{* *}$ & 3.38 \\
TL(Sense-making) & $-1.21^{* *}$ & .35 & -1.83 & 1.32 & $38.85^{* *}$ & 3.38 \\
TL(Expectations) & $-1.09^{*}$ & .36 & -1.92 & 1.35 & $39.56^{* *}$ & 3.45 \\
TL(Team feedback) & $-0.61^{*}$ & .38 & -2.01 & 1.50 & $44.01^{* *}$ & 3.83 \\
TL(Grow Members) & $-1.11^{*}$ & .35 & -1.84 & 1.32 & $38.67^{* *}$ & 3.37 \\
TL(Structure \& Plan) & $-1.14^{*}$ & .36 & -2.06 & 1.35 & $39.65^{* *}$ & 3.45 \\
\hline
\end{tabular}

Note. ${ }^{*} \mathrm{p}<.05,{ }^{*} \mathrm{p}<.001$ 
Table 4

Fixed effects estimates and variance-covariance estimates for models of the predictors for defining the team mission

\begin{tabular}{|c|c|c|c|c|c|c|c|}
\hline Effects & Model 1 & Model 2 & Model 3 & Model 4 & Model 5 & $\begin{array}{c}\text { Final } \\
\text { Model }\end{array}$ & $\begin{array}{c}\text { Effect } \\
\text { Size }\end{array}$ \\
\hline \multicolumn{8}{|l|}{ Fixed effects } \\
\hline Intercept & $-1.12 *$ & $-2.40 * *$ & $-3.27 * *$ & $-3.14 * *$ & -2.92 & $-2.40 * *$ & .59 \\
\hline \multicolumn{8}{|l|}{ Level 1} \\
\hline $\mathrm{X}_{1}$ Task interdependence & & $.52 * *$ & $.52 * *$ & $.53 * *$ & $.51 * *$ & $.52 * *$ & .32 \\
\hline $\mathrm{X}_{2}$ PC (preference) & & & .29 & & & & \\
\hline $\mathrm{X}_{3}$ PC(acceptance) & & & & .23 & & & \\
\hline $\mathrm{X}_{4}$ Self-efficacy team & & & & & .01 & & \\
\hline \multicolumn{8}{|l|}{ Random effects: } \\
\hline \multicolumn{8}{|l|}{ (Team-level) } \\
\hline Intercept/intercept & -1.94 & -2.23 & -2.16 & -2.10 & -2.22 & -2.23 & \\
\hline \multicolumn{8}{|l|}{ (Individual-level) } \\
\hline Intercept/intercept & $38.75 * *$ & $34.99 * *$ & $34.57 * *$ & $34.60 * *$ & $34.97 * *$ & $34.99 * *$ & \\
\hline -2 (Log-Likelihood) & 2004.42 & 1968.40 & 1965.03 & 1965.84 & 1968.28 & 1968.40 & \\
\hline
\end{tabular}

Note. ${ }^{*} \mathrm{p}<.05,{ }^{* *} \mathrm{p}<.001$ 
Table 5

Fixed effects estimates and variance-covariance estimates for models of the predictors of sense-making

\begin{tabular}{|c|c|c|c|c|c|c|c|}
\hline Effects & Model 1 & Model 2 & Model 3 & Model 4 & Model 5 & $\begin{array}{c}\text { Final } \\
\text { Model }\end{array}$ & $\begin{array}{c}\text { Effect } \\
\text { Size } \\
\end{array}$ \\
\hline \multicolumn{8}{|l|}{ Fixed effects } \\
\hline Intercept & $-1.21 * *$ & $-2.48 * *$ & $-3.32 * *$ & $-3.23 * *$ & $-3.13 *$ & $-2.48 * *$ & .60 \\
\hline \multicolumn{8}{|l|}{ Level 1} \\
\hline $\mathrm{X}_{1}$ Task interdependence & & $.52 * *$ & $.52 * *$ & $.52 * *$ & $.51^{* *}$ & $.52 * *$ & .32 \\
\hline $\mathrm{X}_{2}$ PC (preference) & & & .28 & & & & \\
\hline $\mathrm{X}_{3}$ PC(acceptance) & & & & .23 & & & \\
\hline $\mathrm{X}_{4}$ Self-efficacy team & & & & & .01 & & \\
\hline \multicolumn{8}{|l|}{ Random effects: } \\
\hline \multicolumn{8}{|l|}{ (Team-level) } \\
\hline Intercept/intercept & -1.83 & -2.19 & -2.13 & -2.04 & -2.18 & -2.19 & \\
\hline \multicolumn{8}{|l|}{ (Individual-level) } \\
\hline Intercept/intercept & $38.85 * *$ & $35.20 * *$ & $34.82 * *$ & $34.78 * *$ & $35.17 * *$ & $35.20 * *$ & \\
\hline -2 (Log-Likelihood) & 2006.13 & 1970.75 & 1967.70 & 1968.13 & 1970.56 & 1970.75 & \\
\hline
\end{tabular}

Note. ${ }^{*} \mathrm{p}<.05, * * \mathrm{p}<.001$ 
Table 6

Fixed effects estimates and variance-covariance estimates for models of the predictors for establish expectations

\begin{tabular}{|c|c|c|c|c|c|c|c|}
\hline Effects & Model 1 & Model 2 & Model 3 & Model 4 & Model 5 & $\begin{array}{c}\text { Final } \\
\text { Model }\end{array}$ & $\begin{array}{c}\text { Effect } \\
\text { size }\end{array}$ \\
\hline \multicolumn{8}{|l|}{ Fixed effects } \\
\hline Intercept & $-1.09 *$ & $-2.37 * *$ & $-3.22 * *$ & $-3.11 * *$ & -2.98 & $-2.37 * *$ & .58 \\
\hline \multicolumn{8}{|l|}{ Level 1} \\
\hline $\mathrm{X}_{1}$ Task interdependence & & $.53 *$ & $.52 * *$ & $.53 * *$ & $.51 * *$ & $.53 *$ & .32 \\
\hline $\mathrm{X}_{2}$ PC (preference) & & & .28 & & & & \\
\hline $\mathrm{X}_{3}$ PC(acceptance) & & & & .23 & & & \\
\hline $\mathrm{X}_{4}$ Self-efficacy team & & & & & .01 & & \\
\hline \multicolumn{8}{|l|}{ Random effects: } \\
\hline \multicolumn{8}{|l|}{ (Team-level) } \\
\hline Intercept/intercept & -1.92 & -2.28 & -2.19 & -2.14 & -2.27 & -2.28 & \\
\hline \multicolumn{8}{|l|}{ (Individual-level) } \\
\hline Intercept/intercept & $39.56 * *$ & $35.81 * *$ & $35.39 * *$ & $35.41^{* *}$ & $35.79 * *$ & $35.81^{* *}$ & \\
\hline -2 (Log-Likelihood) & 2011.24 & 1975.64 & 1972.53 & 1973.15 & 1975.49 & 1975.64 & \\
\hline
\end{tabular}

Note. ${ }^{*} \mathrm{p}<.05, * * \mathrm{p}<.001$ 
Table 7

Fixed effects estimates and variance-covariance estimates for models of the predictors for provide feedback to team

\begin{tabular}{|c|c|c|c|c|c|c|c|}
\hline Effects & Model 1 & Model 2 & Model 3 & Model 4 & Model 5 & $\begin{array}{c}\text { Final } \\
\text { Model }\end{array}$ & $\begin{array}{c}\text { Effect } \\
\text { size }\end{array}$ \\
\hline \multicolumn{8}{|l|}{ Fixed effects } \\
\hline Intercept & -0.61 & $-1.98 * *$ & $-2.90 * *$ & $-2.80 * *$ & -2.72 & $-1.98 * *$ & .49 \\
\hline \multicolumn{8}{|l|}{ Level 1} \\
\hline $\mathrm{X}_{1}$ Task interdependence & & $.56 * *$ & $.56^{* *}$ & $.56^{* *}$ & $.55 * *$ & $.56 * *$ & .32 \\
\hline $\mathrm{X}_{2}$ PC (preference) & & & .30 & & & & \\
\hline $\mathrm{X}_{3}$ PC(acceptance) & & & & .25 & & & \\
\hline $\mathrm{X}_{4}$ Self-efficacy team & & & & & .01 & & \\
\hline \multicolumn{8}{|l|}{ Random effects: } \\
\hline \multicolumn{8}{|l|}{ (Team-level) } \\
\hline Intercept/intercept & -2.01 & -2.39 & -2.29 & -2.22 & -2.39 & -2.39 & \\
\hline \multicolumn{8}{|l|}{ (Individual-level) } \\
\hline Intercept/intercept & $44.01 * *$ & $39.72 * *$ & $39.24 * *$ & $39.28 * *$ & $39.69 * *$ & $39.72 * *$ & \\
\hline -2 (Log-Likelihood) & 2045.31 & 2008.88 & 2005.68 & 2006.20 & 2008.68 & 2008.88 & \\
\hline
\end{tabular}

Note. ${ }^{*} \mathrm{p}<.05, * * \mathrm{p}<.001$ 
Table 8

Fixed effects estimates and variance-covariance estimates for models of the predictors for grow team members

\begin{tabular}{|c|c|c|c|c|c|c|c|}
\hline Effects & Model 1 & Model 2 & Model 3 & Model 4 & Model 5 & $\begin{array}{c}\text { Final } \\
\text { Model }\end{array}$ & $\begin{array}{c}\text { Effect } \\
\text { size }\end{array}$ \\
\hline \multicolumn{8}{|l|}{ Fixed effects } \\
\hline Intercept & $-1.11 *$ & $-2.40 * *$ & $-3.28 * *$ & $-3.17 * *$ & -2.99 & $-2.40 * *$ & .59 \\
\hline \multicolumn{8}{|l|}{ Level 1} \\
\hline $\mathrm{X}_{1}$ Task interdependence & & $.53 * *$ & $.53 * *$ & $.53 * *$ & $.52 * *$ & $.53 * *$ & .32 \\
\hline $\mathrm{X}_{2} \mathrm{PC}$ (preference) & & & .29 & & & & \\
\hline $\mathrm{X}_{3} \mathrm{PC}$ (acceptance) & & & & .23 & & & \\
\hline $\mathrm{X}_{4}$ Self-efficacy team & & & & & .01 & & \\
\hline \multicolumn{8}{|l|}{ Random effects: } \\
\hline \multicolumn{8}{|l|}{ (Team-level) } \\
\hline Intercept/intercept & -1.84 & -2.19 & -2.11 & -2.05 & -2.18 & -2.19 & \\
\hline \multicolumn{8}{|l|}{ (Individual-level) } \\
\hline Intercept/intercept & $38.67 * *$ & $34.86^{* *}$ & $34.43 * *$ & $34.44 * *$ & $34.83 * *$ & $34.86 * *$ & \\
\hline -2 (Log-Likelihood) & 2004.48 & 1967.51 & 1964.14 & 1964.82 & 1967.82 & 1967.51 & \\
\hline
\end{tabular}

Note. ${ }^{*} \mathrm{p}<.05, * * \mathrm{p}<.001$ 
Table 9

Fixed effects estimates and variance-covariance estimates for models of the predictors for structure and plan

\begin{tabular}{|c|c|c|c|c|c|c|c|}
\hline Effects & Model 1 & Model 2 & Model 3 & Model 4 & Model 5 & $\begin{array}{c}\text { Final } \\
\text { Model }\end{array}$ & $\begin{array}{c}\text { Effect } \\
\text { size }\end{array}$ \\
\hline \multicolumn{8}{|l|}{ Fixed effects } \\
\hline Intercept & $-1.14 *$ & $-2.42 * *$ & $-3.28 * *$ & $-3.16 * *$ & -3.18 & $-2.42 * *$ & .58 \\
\hline \multicolumn{8}{|l|}{ Level 1} \\
\hline $\mathrm{X}_{1}$ Task interdependence & & $.53 * *$ & $.52 * *$ & $.53 * *$ & $.51 * *$ & $.53 * *$ & .32 \\
\hline $\mathrm{X}_{2} \mathrm{PC}$ (preference) & & & .28 & & & & \\
\hline $\mathrm{X}_{3} \mathrm{PC}$ (acceptance) & & & & .23 & & & \\
\hline $\mathrm{X}_{4}$ Self-efficacy team & & & & & .01 & & \\
\hline \multicolumn{8}{|l|}{ Random effects: } \\
\hline \multicolumn{8}{|l|}{ (Team-level) } \\
\hline Intercept/intercept & -2.06 & -2.39 & -2.29 & -2.33 & -2.39 & -2.39 & \\
\hline \multicolumn{8}{|l|}{ (Individual-level) } \\
\hline Intercept/intercept & $39.65^{* *}$ & $35.91 * *$ & $35.48 * *$ & $35.59 * *$ & $35.88 * *$ & $35.91 * *$ & \\
\hline -2 (Log-Likelihood) & 2010.97 & 1975.56 & 1972.42 & 1973.10 & 1975.32 & 1975.56 & \\
\hline
\end{tabular}

Note. ${ }^{*} \mathrm{p}<.05,{ }^{* *} \mathrm{p}<.001$ 